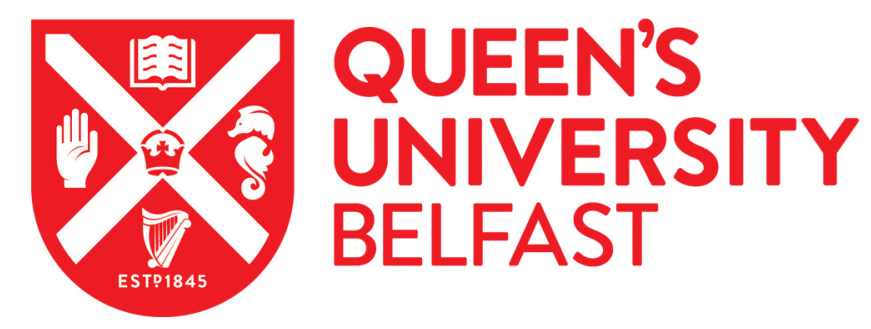

\title{
Structural and Functional Lung Impairment in Adult Survivors of Bronchopulmonary Dysplasia
}

Caskey, S., Gough, A., Rowan, S., Gillespie, S., Clarke, J., Riley, M., Megarry, J., Nicholls, P., Patterson, C., Halliday, H. L., Shields, M. D., \& McGarvey, L. (2016). Structural and Functional Lung Impairment in Adult Survivors of Bronchopulmonary Dysplasia. Annals of the American Thoracic Society, 13(8), 1262-1270. https://doi.org/10.1513/AnnalsATS.201509-5780C

Published in:

Annals of the American Thoracic Society

Document Version:

Peer reviewed version

Queen's University Belfast - Research Portal:

Link to publication record in Queen's University Belfast Research Portal

\section{Publisher rights}

Originally Published in: Steven Caskey, Aisling Gough, Stephen Rowan, Scott Gillespie, Jim Clarke, Marshall Riley, Jacqui Megarry, Paul Nicholls, Chris Patterson, Henry L. Halliday, Michael D. Shields, and Lorcan McGarvey "Structural and Functional Lung Impairment in Adult Survivors of Bronchopulmonary Dysplasia", Annals of the American Thoracic Society, Vol. 13, No. 8 (2016), pp. 1262-1270.

DOI: 10.1513/AnnalsATS.201509-5780C

Copyright $\left({ }^{\circ} 2016\right.$ by the American Thoracic Society

The final publication is available at http://www.atsjournals.org/doi/10.1513/AnnalsATS.201509-578OC\#.V8hLg_krJhE

\section{General rights}

Copyright for the publications made accessible via the Queen's University Belfast Research Portal is retained by the author(s) and / or other copyright owners and it is a condition of accessing these publications that users recognise and abide by the legal requirements associated with these rights.

Take down policy

The Research Portal is Queen's institutional repository that provides access to Queen's research output. Every effort has been made to ensure that content in the Research Portal does not infringe any person's rights, or applicable UK laws. If you discover content in the Research Portal that you believe breaches copyright or violates any law, please contact openaccess@qub.ac.uk. 
Structural and functional lung impairment in adult survivors of bronchopulmonary dysplasia

Steven Caskey ${ }^{1}$, Aisling Gough ${ }^{1}$, Stephen Rowan ${ }^{1}$, Scott Gillespie ${ }^{2}$, Jim Clarke ${ }^{2}$, Marshall Riley $^{3}$, Jacqui Megarry ${ }^{3}$, Paul Nicholls ${ }^{4}$, Chris Patterson ${ }^{5}$, Henry L Halliday $^{6}$, Michael D. Shields ${ }^{1}$, Lorcan McGarvey ${ }^{1}$

Affiliations: ${ }^{1}$ Centre for Infection and Immunity, Queen's University Belfast, Belfast, ${ }^{2}$ Imaging Centre, Royal Victoria Hospitals, Belfast, Belfast Health and Social Care Trust, ${ }^{3}$ Regional Respiratory Centre, Belfast City Hospital, Belfast, Belfast Health and Social Care Trust, ${ }^{4}$ Department of Medicine, Royal Victoria Hospital, Belfast, Belfast Health and Social Care Trust, ${ }^{5}$ Centre for Public Health, Queen's University Belfast, Belfast, ${ }^{6}$ Regional Neonatal Unit, Royal Jubilee Maternity Hospital, Belfast Health and Social Care Trust.

Corresponding author: Dr Lorcan McGarvey MD, FRCP

Address: Centre for Infection and Immunity, Wellcome Wolfson Institute of Experimental Medicine, Queen's University Belfast, Belfast, N. Ireland email: I.mcgarvey@qub.ac.uk

Word count: 4611 
Author contribution: The study was conceived and designed by Lorcan McGarvey, Michael Shields, Chris Patterson and Henry Halliday. Steven Caskey performed data collection and with Lorcan McGarvey prepared the first draft of the manuscript. Michael Shields, Chris Patterson and Henry Halliday assisted with data interpretation and preparation of subsequent versions of the manuscript. Lorcan McGarvey was Principal Investigator and is Guarantor for the manuscript. Scott Gillespie and James Clarke scored CT scans and assisted in manuscript preparation. Jacqui Megarry, Marshall Riley and Paul Nicholls provided assistance with conduct and interpretation of cardiopulmonary exercise testing. Stephen Rowan assisted with the multiple breath washout testing and interpretation.

\section{Financial /nonfinancial disclosures}

This study received financial support from The Northern Ireland Chest, Heart and Stroke Association. The sponsor had no role in the design of the study, the collection and analysis of the data, or in the preparation of the manuscript.

Short running title: Structural and functional lung impairment in adult survivors of bronchopulmonary dysplasia

Key words: Bronchopulmonary dysplasia, adult, chronic lung disease

This article has an online data supplement, which is accessible from this issue's table of content online at www.atsjournals.org 


\section{Abstract}

Rationale: With increasing survival of preterm infants with bronchopulmonary dysplasia (BPD) it is critical to understand the clinical consequences on adult lung health.

Objectives: To assess structural and functional lung parameters in young adult BPD survivors and preterm and term controls

Methods: Young adult survivors of BPD (mean age 24) underwent spirometry, lung volumes, transfer factor, lung clearance index and fractional exhaled nitric oxide measurements together with high-resolution chest tomographic CT imaging and cardiopulmonary exercise testing.

Measurements and main results: 25 adult BPD survivors, (mean \pm SD gestational age (GA) $26.8 \pm 2.3$ weeks; birth weight $866 \pm 255$ g), 24 adult prematurely born non-BPD controls (GA $30.6 \pm 1.9$ weeks; birth weight $1234 \pm 207 \mathrm{~g}$ ) and 25 adult term birth controls (GA $38.5 \pm 0.9$ weeks; and birth weight $3569 \pm 2979 \mathrm{~g}$ ) were studied. BPD subjects were more likely to be wakened by cough (OR 9.7, $95 \% \mathrm{Cl}: 1.8$ to 52.6 ), $p<0.01$ ), wheeze and breathlessness (OR $12.2,95 \% \mathrm{Cl}: 1.3$ to 112$), p<0.05)$ than term controls after adjusting for gender and current smoking. Preterm subjects had greater airways obstruction than term subjects. BPD subjects 
had significantly lower values for $\mathrm{FEV}_{1}$ and $\mathrm{FEF}_{25-75}$ (\% predicted and $\mathrm{z}$ scores) than term controls (both $\mathrm{p}<0.001$ ). Although non-BPD subjects also had lower spirometric values than term controls, none of the differences reached statistical significance. More BPD subjects (25\%) had fixed airflow obstruction than non-BPD (12.5\%) and term (0\%) subjects $(p=0.004)$. Both BPD and non-BPD subjects had significantly greater impairment in gas transfer (Kco \% predicted) than term subjects (both $\mathrm{p}<0.05$ ). Eighteen (37\%) preterm participants were classified as small for gestational age (birth weight $<10$ th percentile for gestational age). These subjects had significantly greater impairment in $\mathrm{FEV}_{1}$ (\% predicted and z scores) than those born appropriate for gestational age. BPD survivors had significantly more severe radiographic structural lung impairment than non-BPD subjects. Both preterm groups had impaired exercise capacity compared to term controls. There was a trend for greater limitation and leg discomfort in BPD survivors.

Conclusions: Adult preterm birth survivors, especially those who developed BPD, continue to experience respiratory symptoms and exhibit clinically important levels of pulmonary impairment.

Abstract word count: 350 
Children born prematurely and especially those who develope bronchopulmonary dysplasia (BPD) have more respiratory symptoms $(1,2)$ and greater lung function impairment persisting through adolescence than term born peers $(2,3,4)$ Consequently concerns regarding the longer-term consequences of BPD include the early development of chronic obstructive pulmonary disease (COPD) $(5,6)$. The adult respiratory health outcomes of BPD survivors are not well defined and our recent systematic review highlighted the limited number of small studies, some without suitable study controls (7).

Although we have recently undertaken a study of adult survivors of BPD in their third and fourth decade of life and reported increased respiratory symptoms and substantial and clinically important reductions in lung function variables reflecting airflow obstruction compared to preterm and term controls, important knowledge gaps remain. Specifically, it is unclear whether lung impairment extends beyond the airway and if lung injury in early preterm life is associated with structural damage to surrounding lung tissue. 
One small study of highly selected and symptomatic adult BPD subjects reported striking structural damage including emphysema (8). Furthermore lung impairment may only become apparent during exercise and to date results from cardiopulmonary exercise testing have been conflicting. Vrijlandt and colleagues (9) confirmed reduced peak oxygen consumption in young adult BPD subjects compared to healthy controls. Lovering and colleagues (10) confirmed significantly reduced peak work rates and greater leg discomfort during exercise in preterm non-BPD and BPD subjects compared to term controls. In contrast, Narang et al (11), found no evidence of exercise limitation in ex preterm subjects compared to term controls.

Based on the accumulating evidence we hypothesised greater structural and functional lung impairment in adult BPD survivors compared to preterm and term controls. Here we report on lung function (spirometry, lung volumes, diffusing capacity), lung clearance index, fractional exhaled nitric oxide (FeNO) measurements, exercise capacity and high resolution $\mathrm{CT}$ (HRCT) findings in an index group of adult survivors of BPD compared to preterm and term controls. We used a subset of our Premature Adult Lung Study (PALS) cohort which was previously published (12) and reported in abstract form $(13,14,15,16,17)$.

\section{Methods}

\section{Study design and participants}

The PALS cohort comprised adults previously cared for in the Regional Neonatal Intensive Care Unit (NICU) of the Royal Maternity Hospital, Belfast between January 1978 and April 1993. This unit was the regional centre providing a comprehensive neonatal service and received patients from all over Northern Ireland. 
BPD was defined as the continued requirement for supplemental oxygen $>28$ postnatal days with chronic radiological changes and severity (mild, moderate or severe) was graded according to oxygen requirements at 36 weeks post menstrual age (18). BPD subjects were compared with gender matched preterm non-BPD controls also cared for in the NICU but not requiring mechanical ventilation or prolonged respiratory support. Both preterm groups were of very low birth weights (VLBW: < 1500g). A second control group comprising full term individuals, with no history of respiratory disease was recruited.

Tracing and recruitment to PALS and this sub study (Figure E1) is detailed in the online supplement. Consecutive subjects responding to an invitation to participate in this sub study and meeting study criteria were recruited. Subjects were excluded if physical or cognitive impairment was likely to prevent them undertaking study procedures. (See online supplement for full protocol). All participants gave written informed consent and the study was approved by the Office for Research Ethics Committees Northern Ireland (ORECNI, 11/NI/0042).

\section{Testing Protocol: Visit one}

Respiratory symptoms were recorded using the European Community Respiratory Health Survey (ECRHS) screening tool (19). Quality of life was measured using the EuroQol (20) and lung function tests were carried out in the order described below.

Multiple breath washout tests were performed using a modified Innocor ${ }^{\mathrm{TM}}$ gas analyser (Innovision ${ }^{\mathrm{TM}} \mathrm{A} / \mathrm{S}$, Odense, Denmark) and an open-circuit technique (21) with the lung 
clearance index calculated. FeNO was measured using the (NIOX ${ }^{\mathrm{TM}}$ MINO (Aerocrine AB, Sweden) according to ATS/ERS recommendations (22).

Forced Vital Capacity (FVC), and Forced Expiratory Volume in one second (FEV 1 ) and mid expiratory flow (FEF $25-75$ ) were measured in accordance with ATS/ERS guidance (23) using a Sensoromics Vmax Encore (Conshohocken, USA). Spirometric results were expressed as percent predicted and z-scores based on prediction equations provided by the Institute of Child Health (24).

Total Lung Capacity (TLC) and Residual Volume (RV) were measured using Helium dilution. Diffusing capacities were measured using single breath diffusing capacity tests. Subjects omitted regular asthma medication the morning of testing.

BPD subjects and non-BPD controls underwent inspiratory and expiratory HRCT imaging of the chest on a 64-slice CT scanner (Siemens AG, Germany). All scans were scored independently and blindly by two expert radiologists (SG, JC) using a validated standardised scoring method (Table E1 online supplement) (25).

\section{Testing Protocol: Visit Two}

Exercise testing was performed using a standardised, symptom-limited, maximal exercise protocol, (Modified Bruce Protocol) (26) using ATS guidelines (27). Peak $\mathrm{VO}_{2}$ was defined as the average $\mathrm{VO}_{2}$ over the final 30 seconds of exercise. The anaerobic threshold was determined using the $\mathrm{V}$ slope method by two experienced observers (SC, JM). Exercise data were plotted as time weighted 10 second averages. 


\section{Statistical analysis}

Continuous variables were summarised as mean (standard deviation, SD) if normally distributed and median (interquartile range, IQR) if skewed. For normally distributed variables group comparisons were made using one-way ANOVA (with Tukey's post-hoc all pairs simultaneous $95 \%$ confidence intervals for mean differences and $p$-values) or t-tests.

For non-normally distributed variables group comparisons were made using Kruskal-Wallis test (with Dunn's all pairs post-hoc testing) or Mann-Whitney U tests. Categorical variables were summarised as proportions and comparisons performed using the chi-square test (or Fisher's exact test, where appropriate) and summarised as odds ratios.

We used linear regression modelling to compare lung function for those with BPD and Preterm Non BPD whilst adjusting for birth weight, gestational age and year of birth. Logistic regression was used to compare symptoms between groups whilst adjusting for gender and current smoking status.

We undertook analysis to determine the effect of low birth weight for GA by comparing those born small for gestational age (SGA) with those born at an appropriate weight for gestation (AGA). SGA was defined as a birth weight $<10$ th percentile for gestational age using the 1990 British Growth Standard (28). These comparisons of SGA and AGA subgroups required weighting to take account of the different selection probabilities for the BPD and non-BPD subgroups inherent in our study design. 
SPSS version 20 (IBM Corp., Armonk, New York), Minitab 17 (Minitab Inc., State College, Pennsylvania) and Stata release 12 (Stata Corp, College Stations, Texas) were used in the statistical analysis. A p-value $\leq 0.05$ was taken as statistically significant

\section{Results}

Twenty five BPD subjects (mean (SD) age 24.0 (3.4)y, range 19 to 33y) were enrolled and compared with 24 non-BPD controls (mean (SD) age 26.4 (3.7)y, range 21 to $34 \mathrm{y}$ ) and 25 term controls (mean (SD) age 28.3(3.3)y, range 22 to 33y). Of these, 23 BPD subjects (15\% of the original 153 identified from labour records) and 23 non BPD (7\% of original 322 non-BPD subjects from labour records) completed all parts of this study.

Term controls comprised 12 (2\% of original 492 identified from labour records) and 13 healthy volunteers born term with known birth weight and GA recruited from hospital staff. Participant demographics are detailed in Table 1.

BPD subjects had a lower gestational age [mean 26.8 weeks (SD 2.3, range 23 to 30 weeks)] compared to non-BPD subjects [mean 30.6 (SD 1.9, range 26 to 34) weeks] and lower birth weight [mean 866 (SD 255, range 510 to 1490) grams] compared to non-BPD subjects [mean 1234 (SD 205, range 760 to 1500) grams, (both $p<0.001$ )].

Current smoking status, BMI and physician diagnosed asthma were not significantly different among groups. One BPD subject was receiving inhaled corticosteroids and a short acting beta 2 agonist and 2 others were prescribed short acting beta 2 agonists alone. No non-BPD subjects were prescribed inhaled corticosteroids although one was prescribed a short acting 
beta 2 agonist. One term control had been prescribed an inhaled corticosteroid/long acting beta 2 agonist while 3 others took short acting beta 2 agonists alone.

There were no significant differences in gestation between BPD subjects recruited and those not responding to invitation but the responders were on average 150 lighter in birth weight (Table E2, online supplement).

\section{Respiratory symptoms}

BPD subjects were at almost 10 times more likely to report being woken by coughing (OR 9.7, $95 \% \mathrm{Cl}: 1.8$ to 52.6$), p<0.01)$, and were over 4 times more likely to report being breathless when wheezing (OR $4.3,95 \% \mathrm{Cl}: 1.1$ to 16.8 ), $p<0.05$ ) in the last 12 months compared to term controls after adjusting for gender and current smoking (Table E3 online supplement). BPD subjects had significantly lower EQ-5D utility score than term controls $(p<0.01)$ and reported lower scores on EQ-5D VAS compared with non-BPD, although this was not statistically significant (Table E4, online supplement).

\section{Lung function}

Significant differences were apparent between the 3 groups in all lung function tests with the exception of RV \% predicted, TLC \% predicted and RV/TLC ratio (Table 2 and Figure 1). BPD subjects had significantly lower values for all spirometric measures than term controls. Although non-BPD subjects also had lower spirometric values than term controls, none of the differences reached statistical significance.

BPD subjects had significantly lower mean values for $\mathrm{FEV}_{1}, \mathrm{FVC}$ and $\mathrm{FEF}_{25-75}$ compared to non-BPD controls whether expressed as percent predicted or z-scores (Table 2). Of the 7 BPD 
subjects who had an $\mathrm{FEV}_{1} / \mathrm{FVC}$ ratio $<70 \%$ predicted only 2 had significant reversibility defined as change in $\mathrm{FEV}_{1}$ of $>400 \mathrm{mls}$ and $\mathrm{FEV}_{1} \%$ predicted $>15 \%$ after bronchodilator (23).

While not statistically significant, RV/TLC ratios were higher in the BPD subjects than preterm and term controls. Diffusing capacities $\mathrm{TL}_{\mathrm{co}}$ and $\mathrm{K}_{\mathrm{co}} \%$ predicted values were similar in BPD and non-BPD subjects and both were significantly lower than term controls (both $p<0.001$ ). Significantly more BPD subjects had airflow reductions in the abnormally low range defined as $\mathrm{FEV}_{1}<80 \%$ predicted, $\mathrm{FEV}_{1} / \mathrm{FVC}<70 \%, \mathrm{FEF}_{25-75}<60 \%$ predicted, $\mathrm{TL}_{\mathrm{co}} \%$ predicted $<80 \%$, $\mathrm{K}_{\mathrm{co}} \%$ predicted $<80 \%$ ). Almost one quarter of the BPD group had $\mathrm{FEV}_{1}<80 \%$ compared to none of the term controls. Similarly, $60 \%$ of BPD subjects had $\mathrm{FEF}_{25-75}<60 \%$ compared to less than $5 \%$ of term controls.

Abnormally increased RV/TLC ratios (i.e. $>120 \%$ predicted) were recorded in $38 \%$ of BPD subjects compared with less than $5 \%$ of term controls. $43 \%$ of BPD subjects had abnormally low $\mathrm{TL}_{\mathrm{CO}} \%$ predicted and $23 \%$ abnormally low $\mathrm{K}_{\mathrm{CO}} \%$ predicted compared to term controls ( $4 \%$ and $0 \%$ respectively) (both $p<0.01$ ). Compared to non-BPD controls, significantly more BPD subjects had abnormally low $\mathrm{FEF}_{25-75} \%$ predicted values $(p<0.01)$ (Table E5 online supplement).

As our study population comprised adults born preterm over a 15 year time span we considered the possibility that our comparisons of groups could be confounded by birth cohort effects as well as by birth weight and gestational age differences. Regression analysis of the lung function measurements (Table E6 online supplement). 


\section{Lung Clearance Index}

Lung clearance index scores were significantly higher in BPD subjects [median (IQR) 7.0 (6.7-

7.9)] compared to non-BPD [6.1 (5.9-6.9)] and term controls [6.6 (5.9-7.0)] $(p=0.016$ and $p=0.003)$. Using our recently published normal values [mean (SD) $6.5(0.5)$ ] for lung clearance index by multiple breath washout on the same device in a cohort $(n=30)$ of healthy controls (Section E1.2) (29) more BPD subjects $(n=6)$ had abnormal lung clearance index values (> 1.96 SD score i.e. $>7.5)$ compared with non-BPD $(n=2)$ and term $(n=1)$ controls $(p=0.055)$. Thirty percent of BPD subjects with normal $\mathrm{FEV}_{1}(>80 \%$ predicted) had abnormal lung clearance index measurements (22).

\section{FeNO measurements}

Although FeNO measurements were lower in both BPD subjects (median 19, IQR: 12 to 28 ppb) and non-BPD controls (median 19, IQR: 12 to $28 \mathrm{ppb}$ ) compared to term controls (median 27, IQR: 14 to $43 \mathrm{ppb)} \mathrm{neither} \mathrm{result} \mathrm{attained} \mathrm{statistical} \mathrm{significance.}$

Lung function of subjects with low versus appropriate birth weight for gestational age Eighteen (37\%) preterm participants were classified as SGA (birth weight $<10^{\text {th }}$ percentile for gestational age). Data are presented in table 3. The SGA participants had been born at significantly greater gestational age than AGA (mean difference $(95 \% \mathrm{Cls}),-2.4$ weeks $(1.5$ to 4.1), $p<0.001$ ). SGA subjects had significantly greater impairment in FEV1 (\% predicted than those born AGA (mean difference $(95 \% \mathrm{Cl}),-9.8(-19.3$ to -0.2$), p<0.05)$ but this difference did not retain its significance after weighting the analysis to allow for the higher sampling 
fraction of BPD subjects than non-BPD subjects. Those with BPD were no more likely to be SGA as preterm non-BPD ( $32 \%$ versus $42 \%$, chi-squared $p=0.69$ ).

\section{HRCT chest Imaging}

BPD subjects had higher HRCT scan severity scores than non-BPD $(p=0.0001)$ and all BPD subjects had some degree of HRCT abnormality (Figure E2 and E3, Table 4). Sub-pleural opacities were the most common abnormality detected, and more common in BPD than non-BPD subjects ( $96 \% \vee 43 \%, p<0.001)$. Hypoattenuation on expiration (gas trapping) and bullous disease were significantly more common in BPD than non-BPD $(65 \%$ v $30 \%$, and $22 \%$ $v 0 \%$, both $p<0.05)$. There were no significant differences in emphysema, bronchiectasis or bronchial wall thickening between groups.

When all preterm subjects were considered together, increasing HRCT score severity correlated significantly with measures of airflow obstruction (lower $\mathrm{FEV}_{1}$ z-scores, $\mathrm{FEV}_{1} / \mathrm{FVC}$ z-scores, $\mathrm{FEF}_{25-75} \mathrm{z}$-scores) and hyperinflation (increased $\mathrm{RV} / \mathrm{TLC}$ ratio). When only BPD subjects were considered, only the correlation between HRCT score and RV/TLC ratio remained significant.

\section{Cardiopulmonary exercise testing}

Exercise data were obtained from 22 BPD subjects, 20 non-BPD and 24 term controls (Table 5). Two BPD subjects were unable to perform the test because of cerebral palsy. One BPD subject, 2 non-BPD and 1 term control failed to attend. A greater proportion of term controls exercised more than 3 hours/week with no other significant differences in weekly activity levels among study groups. Fatigue and dyspnoea were the most common reason for 
terminating the test in each group. More subjects with BPD $(n=7)$ reported leg discomfort during exercise than non-BPD $(n=4)$ and term controls $(n=3)$.

BPD subjects had significantly lower peak $\mathrm{VO}_{2}$ than term controls [Mean (SD) $\mathrm{ml} / \mathrm{kg} / \mathrm{min}$ : $35.6(7.5)$ vs. $45.2(11.3)(p<0.01)$ and travelled significantly less distance than term controls [Mean (SD) m: 966 (245) vs. 1402 (333) ( $p<0.001)$ ]. Non-BPD controls had significantly lower peak $\mathrm{VO}_{2}$ than term controls [39.3 (8.8) vs. $\left.45.2(11.3)(p<0.05)\right]$ and also travelled significantly less distance than term controls [1143 (303) vs. 1402 (333), p<0.05)]. A number of BPD subjects $(n=6)$ failed to attain $>84 \%$ of their predicted target heart rate. Even when these subjects were excluded the significant differences in peak $\mathrm{VO}_{2}$ between BPD subjects and term controls remained [Mean (SD) ml/kg/min: 36.9 (7.2) vs. 46.1 (10.8) ( $p<0.01)$. BPD subjects achieved lower peak $\mathrm{VO}_{2}$ and travelled shorter distances than non-BPD but these differences were not statistically significant.

At peak exercise, BPD subjects had significantly lower peak heart rates than term controls (mean (SD) bpm: 173(13) vs. $186(14), \mathrm{p}<0.001)$. Ventilatory equivalents for $\mathrm{CO}_{2}$ and $\mathrm{O}_{2}$ at the AT were greater in the BPD group than in the term controls, but there were no significant differences in ventilatory reserve or maximum respiratory rates between BPD subjects and term controls. BPD subjects had significantly lower minute ventilation (VE I/min) [Mean (SD) (I/min): 78.3 (22.7) vs. 109.5 (36.2); ( $p<0.01)$ ] and smaller tidal volume (Vt, L) $[1.75(0.45)$ vs. $2.75(0.67) ;(p<0.001)]$ at peak exercise than term controls. 
Measures of airflow obstruction [FEV $1 \%$ predicted $(r=0.29, p=0.001), \mathrm{FEV}_{1} / \mathrm{FVC}$ ratio $(r=0.01$, $p=0.05)$ and $\mathrm{FEF}_{25-75} \%$ predicted $(r=0.32, p=0.04]$ were significantly correlated with impaired exercise capacity in adult survivors of BPD. However, HRCT scan severity scores were not associated with exercise capacity in preterm adults. There were no neonatal factors that could significantly predict impaired exercise capacity in preterm subjects.

\section{Discussion}

In this study, we confirm that individuals born prematurely, in particular those who developed BPD, have clinically important levels of respiratory morbidity persisting into adulthood. Young adult BPD survivors reported more wheeze, breathlessness and wakening with cough than non-BPD or term controls and significantly more had fixed airflow obstruction in the presence of normal or low FeNO levels and decreased diffusion capacity. BPD survivors had radiological evidence of more severe structural lung impairment than non-BPD controls. We also observed that both preterm groups had impaired exercise capacity compared to term controls with a trend for greater exercise limitation and more leg discomfort during exercise in BPD survivors.

Our findings reaffirm the evidence suggesting adverse long term consequences of preterm birth and BPD on adult respiratory health $(4,11,29-31)$. We extend our previous observations and suggest lung function abnormalities are not confined solely to spirometric end points, but include air trapping and impaired gas transfer (12). In the majority (75\%) of BPD survivors, airflow obstruction was fixed or only partially reversible and was associated with normal or low FeNO values suggesting a non-asthmatic or at least a non-eosinophilic cause for airflow limitation. 
This observation adds support to the concern that perinatal lung injury may predispose to early COPD (6).

In a recent study by Landry and colleagues (32), adults born prematurely with BPD were more likely to have mild airflow obstruction and bronchial hyperresponsiveness than those born prematurely who did not experience BPD. We did not undertake methacholine challenge testing butthe presence of fixed airflow obstruction in a number of our subjects suggests that distinct phenotypic variants of airflow limitation exist in adult survivors of preterm birth.

Significantly lower FVC (\% predicted and z scores) were observed in BPD subjects compared to term born although restrictive defects were not seen as no subjects had FVC and/or TLC measurements below the lower limit of normal. Although mean birth weights were lower in BPD subjects compared to non-BPD adjustment for birth weight did not alter our findings. As none of the non-BPD preterms were ventilated we suspect the inflammatory effects on lung development in early neonatal life due to hyperoxia and barotrauma and possible infection during the periods of mechanical ventilation have contributed to differences between the preterm groups. Lung clearance index measured by multiple breath washout is a measure of ventilation distribution which may become heterogeneous (uneven) early in diseases including asthma (33) and cystic fibrosis (34). We observed a greater proportion of adult BPD survivors with abnormal values compared to term. Although measurements were not as high as reported in bronchiectasis (29) a significant proportion (30\%) of BPD subjects with normal spirometry, had abnormal lung clearance index measurements.

We investigated the association between neonatal factors and lung function in our preterm population. We adjusted for year of birth and found no evidence of a birth cohort effect. We 
sought to determine whether low birth weight for gestational age could explain some of our findings and report that those born SGA had greater lung function impairment than subjects born AGA. Infants with intra-uterine growth retardation are at increased risk of impaired lung function within the first few years of life (35). Here we provide evidence that impairment extends into adulthood.

Structural lung abnormalities on CT scans have been reported in children and adolescents surviving BPD $(25,36)$. We found that BPD subjects have significantly more radiological abnormality compared to non-BPD controls. Subpleural opacities were the most common abnormality observed in almost all (96\%) of our BPD subjects compared with less than half (46\%) of non-BPD subjects. They are thought to be related to fibrotic change within the lung arising from neonatal insults such as hyperoxia and mechanical ventilation. We did not see significant bullous lung disease contrasting the findings of Wong et al, (8). We observed significant inverse relationships between spirometry measurements and HRCT score severity and highlight important 'structure-function' consequences of preterm birth on adult lung health. We observed significantly impaired exercise capacity in preterm subjects (BPD and non BPD) compared to term controls. Following adjustments for sub-maximal exercise tests (Table E9) and general activity levels, these significant differences remained. BPD subjects had numerically greater reductions in peak $\mathrm{VO}_{2}$ and distance travelled on the treadmill than the preterm non-BPD controls which could possibility be due to patient effort as they achieved lower peak heart rates lower RERs. At least some of the reduction in exercise capacity in both our preterm groups may have been due to deconditioning as the $\mathrm{VO}_{2}$ at $\mathrm{AT} /$ peak $\mathrm{VO}_{2}$ was lower in these groups than in term controls. The slightly low oxyhemoglobin saturation and elevated ventilatory equivalents in BPD subjects suggest mild impairment of gas exchange during exercise, but these abnormalities did not limit exercise 
as indicated by the normal ventilatory reserve. Our finding of impaired exercise capacity in adults born preterm is in line Vrijlandt et al (9) but contrasts Narang and colleagues (11), who observed no differences between preterm and term subjects. Their preterm group had relatively well preserved lung function and included few $(n=7)$ BPD subjects. A recent study by Lovering and colleagues (10) identified reduced exercise capacity in adult preterm survivors which was independent of BPD or exercise induced expiratory flow limitation. We did not undertake measurements of expiratory flow or dynamic hyperinflation during exercise. However reduced lung function and low lung diffusion capacity alone do not appear to explain the reduced exercise capacity observed in adult survivors of preterm birth (37). Other unidentified aspects of BPD which might influence exercise performance include deconditioning or perception of fatigue. Landry and colleagues reported that BPD subjects tended to be more sedentary than non-BPD and term subjects (32). In line with Lovering and colleagues (10) a greater proportion of our preterm subjects reported leg discomfort during exercise which may simply reflect deconditioning but does raise the possibility of impaired peripheral muscle function as an additional longer term consequence of preterm birth.

\section{Strengths and Limitations}

A key strength was the ability to trace and study in adulthood, a group of carefully characterised preterm infants (BPD subjects and non-BPD controls) all cared for in the same hospital. Further, our study size was larger than many identified in our systematic literature review (7).

A potential limitation of our study was the relatively low recruitment rates of preterm adults from the infants identified in the original labour records. This may have introduced bias such as exclusion of the most severely affected although the similarity of birth demographics 
between the PALS cohort and those not responding to the study invitation suggests our findings are broadly representative of the general preterm population.

Although less applicable to infants with 'new' BPD arising from extreme prematurity, our findings are relevant to the large number of BPD survivors currently in their third and fourth decade of life many of whom may have unrecognised or incorrectly diagnosed respiratory disease. There is a need for increased awareness as recent evidence suggests that few physicians enquire about neonatal events when assessing their adult patients with pulmonary complaints (38).

None of the non-BPD subjects were ventilated during the neonatal period which does raise a potential bias when directly comparing BPD and non-BPD subjects. Further, non-BPD preterms had higher mean GA and birth weight than BPD preterms and although we undertook linear regression to simultaneously correct for these variables were we not able to adjust for all potential factors.

Finally, as this is a cross-sectional study we have no information on earlier or later lung function trajectories for this cohort. Following preterm cohorts from early life through adulthood into later life is crucial to a complete understanding the consequences of lung injury in the neonatal period.

\section{Conclusions}

Adult survivors of preterm birth have evidence of airflow obstruction which is fixed or only partially reversible. In addition we observed impaired levels of exercise capacity in those 
born preterm compared to full term which could not be explained solely by structural changes or lung function impairment. Whether this impairment is progressive requires longitudinal follow up of preterm cohorts. 


\section{Acknowledgements}

Dr Caskey was funded by a Research Fellowship from NI CHS. He undertook patient recruitment and all study measurements and along with Dr McGarvey wrote the first draft of the manuscript. Professors Halliday and Shields, Drs Gillespie, Clarke and Patterson contributed to the design and analysis of data and with drafting and final approval of the version to be submitted. Dr McGarvey was Principal Investigator and is Guarantor for the manuscript. None of the authors have any competing interests or apparent conflict of interests in relation to the manuscript. 


\section{References}

1. Gray PH, Burns YR, Mohay HA, O'Callaghan MJ, Tudehope DI. Neurodevelopmental outcome of preterm infants with bronchopulmonary dysplasia. Arch Dis Child. 1995;73(3):128-134.

2. Islam JY, Keller RL, Aschner JL, Hartert TV, Moore PE. Understanding the Short- and Long-Term Respiratory Outcomes of Prematurity and Bronchopulmonary Dysplasia. Am J Respir Crit Care Med. 2015;192(2):134-5

3. Fawke J, Lum S, Kirkby J, Hennessy E, Marlow N, Rowell V, Thomas Stocks J. Lung function and respiratory symptoms at 11 years in children born extremely preterm: the EPICure study. Am J Respir Crit Care Med. 2010;182(2):237-245.

4. Doyle LW, Faber B, Callanan C, Freezer N, Ford GW, Davis NM. Bronchopulmonary dysplasia in very low birth weight participants and lung function in adolescence. Pediatrics. 2006;118(1):108-113.

5. Blencowe H, Cousens S, Oestergaard MZ, Chou D, Moller AB, Narwal R, Adler A, Vera Garcia A, Rohde S, Say L, Lawn JE. National, regional and worldwide estimates of preterm birth rates in the year 2010 with time trends for selected countries since 1990: a systematic analysis and implications. Lancet. 2012;379(9832):2162-2172.

6. Baraldi E, Fillipone M. Chronic Lung Disease after Premature Birth. N Eng J Med. $2007 ; 357: 1946-55$

7. Gough A, Spence D, Linden M, Halliday HL, McGarvey LP. General and respiratory health outcomes in adult survivors of bronchopulmonary dysplasia: a systematic review. Chest. 2012;141(6):1554-1567. 
8. Wong PA, Lees AN, Louw J, Lee FY, French N, Gain K, Murray CP, Wilson A, Chambers DC. Emphysema in young adult survivors of moderate-to-severe bronchopulmonary dysplasia. Eur Respir J. 2008;32(2):321-328.

9. Vrijlandt EJLE, Gerritsen J, Boezen HM, Grevink RG, Duiverman EJ. Lung function and exercise capacity in young adults born prematurely. Am J Respir Crit Care Med. 2006;173:890-896.

10. Lovering AT, Elliott JE, Beasley KM, Gust CE, Magnum TS, Gladstone IM, Duke JW. Ventilatory and sensory responses in adult survivors of preterm birth and bronchopulmonary dysplasia with reduced exercise capacity. Ann Am Thorac Soc. 2014;11(10):1528-37

11. Narang I, Rosenthal M, Cremonesini D, Silverman M, Bush A. Longitudinal evaluation of airway function 21 years after preterm birth. Am J Respir Crit Care Med. 2008;178(1):74-80.

12. Gough A, Linden M, Spence D, Patterson CC, Halliday HL, McGarvey LP. Impaired lung function and health status in adult survivors of bronchopulmonary dysplasia. Eur Respir J. 2014;43(3):808-816.

13. Caskey S, Rowan S, Halliday H, Shields MD, McGarvey L. Premature adult lung study (PALS): Spirometry and lung clearance index are impaired in adult survivors of bronchopulmonary dysplasia. Eur Respir J 2012;40(56):414

14. Caskey S, Gillespie S, Clarke J, Halliday H, Shields MD, McGarvey L. Lung function abnormalities and structural lung disease in adult survivors of bronchopulmonary dysplasia. Ir J Med Sci. 2013;182(10):465

15. Caskey S, Shields MD, Halliday H, Gillespie S, Clarke J, McGarvey L. Premature Adult Lung Study (PALS): Lung Function Impairment and Structural Lung Disease in Adult 
Survivors of Bronchopulmonary Dysplasia (BPD). Am J Respir Crit Care Med.

2013;187:3688 (Abstracts edition).

16. Caskey S, Nicholls P, Riley M, Shields MD, Halliday H, McGarvey L. Premature Adult Lung Study: Exercise Capacity in Adult Survivors of Bronchopulmonary Dysplasia (BPD). Am J Respir Crit Care Med. 2013;187:3689 (Abstracts edition).

17. Caskey S, Gillespie S, Clarke J, Halliday H, Shields MD, McGarvey L. Structural lung disease in adult survivors of bronchopulmonary dysplasia. Eur Respir J. 2013;42(57):410

18. Jobe AH, Bancalari E. NICHD/NHLBI/ORD workshop summary. Am J Respir Crit Care Med. 2001;163:1723-1729.

19. Burney PG, Luczynska C, Chinn S, Jarvis D. The European Community Respiratory Health Survey. Eur Respir J. 1994;7(5):954-60.

20. The EuroQol Group. EuroQol-a new facility for the measurement of health-related quality of life. Health Policy. 1990;16:199-208.

21. Horsley AR, Gustafsson PM, Macleod KA, Saunders C, Greening AP, Porteous DJ, Davies JC, Cunningham S, Alton EW, Innes JA. Lung clearance index is a sensitive, repeatable and practical measure of airways disease in adults with cystic fibrosis. Thorax. 2008;63:135-140.

22. Dweik RA, Boggs PB, Erzurum SC, Irvin CG, Leigh MW, Lundberg JO, Olin AC, Plummer AL, Taylor DR. An official ATS clinical practice guideline: Interpretation of exhaled nitric oxide levels (FENO) for clinical applications. Am J Respir Crit Care Med. 2011;184(5):602-15 
23. Miller MR, Hankinson J, Brusasco V, Burgos F, Casaburi R, Coates A, Crapo R, Enright P, van der Grinten CP, Gustafsson P, et al. ATS/ERS Task Force. Standardisation of spirometry. Eur Respir J. 2005;26(2):319-38

24. Stanojevic S, Wade A, Stocks J. Reference values for lung function: past, present and future. Eur Respir J 2010; 36(1):12-9

25. Aukland SM, Rosendahl K, Owens CM, Fosse KR, Elde GE, Halvorsen T. Neonatal bronchopulmonary dysplasia predicts abnormal HRCT in long term survivors of extreme preterm birth. Thorax. 2009;64:405-410.

26. Bruce RA. Exercise testing of patients with coronary heart disease: principles and normal standards. Ann Clin Res 1971;3:323-332.

27. American Thoracic Society/American College of Chest Physicians ATS/ACCP statement on cardiopulmonary exercise testing. Am J Respir Crit Care Med. 2003;167:211-277

28. Cole TJ, Freeman JV, Preece MA. British 1990 growth reference centiles for weight, height, body mass index and head circumference fitted by maximum penalized likelihood. Stat Med. 1998;17(4):407-29

29. Rowan S, Bradley JM, Bradbury I, Lawson J, Lynch T, Gustafsson P, Horsley A, O'Neill K, Ennis M, Elborn S. et al. Lung Clearance Index Is a Repeatable and Sensitive Indicator of Radiological Changes in Bronchiectasis. Am J Respir Crit Care Med. 2014;189(5):586-592.

30. Gibson AM, Reddington C, McBride L, Callanan C, Robertson C, Doyle LW. Lung function in adult survivors of very low birthweight, with and without bronchopulmonary dysplasia. Pediatr Pulmonol. 2014; Sep 5. doi:10.1002/ppul.23093. [Epub ahead of print) 
31. Vollsaeter M, Roksund OD, Eide GE, Markestad T, Halvorsen T. Lung function after preterm birth: development from mid-childhood to adulthood. Thorax. 2013;68(8):767-776

32. Landry JS, Tremblay GM, Li PZ, Wong C, Benedetti A, Taivassalo T. Lung Function and Bronchial Hyperresponsiveness in Adults Born Prematurely. A Cohort Study. Ann Am Thorac Soc. 2016;13(1):17-24

33. Verbanck S, Schuermans D, Meysman M, Paiva M, Vincken W. Noninvasive assessment of airway alterations in smokers: the small airways revisited. Am J Respir Crit Care Med. 2004;170(4):414-419.

34. Horsley AR, Gustafsson PM, Macleod KA, Saunders C, Greening AP, Porteous DJ, Davies JC, Cunningham S, Alton EWF, Innes JA. Lung clearance index is a sensitive, repeatable and practical measure of airways disease in adults with cystic fibrosis. Thorax. 2008;63(2):135-140.

35. Greenough A, Yuksel B, Cheeseman P. Effect of in utero growth retardation on lung function at follow-up of prematurely born infants. Eur Respir J 2004; 24: 731-733

36. Aquino SL, Schechter MS, Chiles C, Ablin DS, Chipps B, Webb WR. High-resolution inspiratory and expiratory CT in older children and adults with bronchopulmonary dysplasia. AJR Am J Roentgenol. 1999;173:963-967.

37. Duke JW, Elliott JS, Laurie SS, Beasley KM, Magnum TS, Hawn JA, Gladstone IM, Lovering AT. Pulmonary gas exchange efficiency during exercise breathing normoxic and hypoxic gas in adults born very preterm with low diffusion capacity. J Appl Physiol. 2014;117(5):473-481 
38. Bolton CE, Bush A, Hurst JR, Kotecha S, McGarvey L, Stocks J, Walshaw MJ. Are early life measures considered when managing respiratory disease? A British Thoracic Society survey of current practice. Thorax. 2010;67(12):1110

\section{Figure legend}

Figure 1: Graphical summary of $\%$ predicted (mean \pm SD) for airflow and gas transfer variables between study groups. BPD subjects had significantly lower values for all displayed measures than term controls groups $\left(\mathrm{FEV}_{1}, \mathrm{FVC}\right.$ and $\mathrm{FEF}_{25-75}$, all $\mathrm{p}<0.001$; $\mathrm{K}_{\mathrm{co}} \mathrm{p}<0.001$ ). Non-BPD subjects also had lower spirometric values than term controls but none of the differences reached statistical significance. BPD subjects had significantly lower mean values for $\mathrm{FEV}_{1}$ and $\mathrm{FEF}_{25-75}$ (\% predicted) (both $\mathrm{p}<0.01$ ) compared to non-BPD controls. 


\section{Table 1: Demographics of study participants}

\begin{tabular}{|c|c|c|c|c|c|c|}
\hline & BPD & Non BPD & Term & BPD vs. non BPD & BPD vs. Term & Non BPD vs. Term \\
\hline Number, $\mathbf{n}$ & 25 & 24 & 25 & & & \\
\hline Birth weight, $\mathrm{g}$ & $866(255)$ & $1234(205)$ & $3569(297)$ & $-369(-544$ to -194$) * * *$ & $-2704(-2877$ to -2530$) * * *$ & $-2335(-2510$ to -2160$) * * *$ \\
\hline Gestational age, wk & $26.8(2.3)$ & $30.6(1.9)$ & $38.5(0.9)$ & $-3.8(-5.0$ to -2.6$) * * *$ & $-11.6(-12.9$ to -10.4$) * * *$ & $-7.9(-9.1$ to -6.6$) * * *$ \\
\hline Duration of IPPV, $h$ & $966(599-1652)$ & $\mathrm{n} / \mathrm{a}$ & $\mathrm{n} / \mathrm{a}$ & & & \\
\hline Duration $\mathrm{O}_{2}>60 \%, \mathrm{~h}$ & $10(2-99)$ & $\mathrm{n} / \mathrm{a}$ & $\mathrm{n} / \mathrm{a}$ & & & \\
\hline Maternal Smoker & $7 / 19(37 \%)$ & $8 / 18(44 \%)$ & $\mathrm{n} / \mathrm{a}$ & 0.7 (0.2 to 2.7$)$ & & \\
\hline Antenatal Steroids & $5 / 25(20 \%)$ & $8 / 24(33 \%)$ & $0 / 25(0 \%)$ & $0.5(0.1$ to 1.8$)$ & & \\
\hline Postnatal Steroids & $10 / 25(40 \%)$ & $0 / 24(0 \%)$ & $0 / 25(0 \%)$ & & & \\
\hline Surfactant & $8 / 25(32 \%)$ & $0 / 24(0 \%)$ & $0 / 25(0 \%)$ & & & \\
\hline Apgar Score $1 \mathrm{~min}$ & $5(3-6)$ & $7(3-8)$ & $\mathrm{n} / \mathrm{a}$ & $-1(-3$ to 0$)$ & & \\
\hline Apgar Score 5 min & $8(7-9)$ & $9(8-9)$ & $\mathrm{n} / \mathrm{a}$ & $-1(-2 \text { to } 0)^{* *}$ & & \\
\hline BPD Moderate or Severe & $13 / 25(52 \%)$ & $\mathrm{n} / \mathrm{a}$ & $\mathrm{n} / \mathrm{a}$ & & & \\
\hline Gender, male & $14 / 25(56 \%)$ & $14 / 24(58 \%)$ & $15 / 25(60 \%)$ & $0.9(0.3$ to 2.8$)$ & $0.8(0.3$ to 2.6$)$ & 0.9 (0.3 to 2.9 ) \\
\hline Age at study, y & $24.0(3.4)$ & $26.4(3.7)$ & $28.3(3.3)$ & $-2.4(-4.8 \text { to } 0.0)^{*}$ & $-4.3(-6.6 \text { to }-1.9)^{* * *}$ & $-1.8(-4.2$ to 0.5$)$ \\
\hline Height, cm & $163.7(10.8)$ & $166.4(11.6)$ & $173.7(7.5)$ & $-2.7(-9.6$ to 4.2$)$ & $-10.0(-16.9 \text { to }-3.2)^{* *}$ & $-7.4(-14.3 \text { to }-0.5)^{*}$ \\
\hline Body mass index, $\mathrm{kg} / \mathrm{m}^{2}$ & $25.0(5.6)$ & $22.7(3.4)$ & $24.9(3.6)$ & $2.3(-0.9$ to 5.4$)$ & $0.1(-3.0$ to 3.1$)$ & $-2.2(-5.3,0.9)$ \\
\hline Physician-diagnosed Asthma & $4 / 25(16 \%)$ & $1 / 24(4 \%)$ & $4 / 25(16 \%)$ & 4.4 (0.4 to 42$)$ & $1.0(0.2$ to 4.5$)$ & $0.2(0.0$ to 2.2$)$ \\
\hline Current smokert & $2 / 25(8 \%)$ & $5 / 24(21 \%)$ & $2 / 25(8 \%)$ & 0.3 (0.1 to 1.9$)$ & 1.0 (0.1 to 7.7$)$ & 3.0 (0.5 to 17$)$ \\
\hline Exercise at least $2-3 \mathrm{hr} /$ week & $6 / 24(25 \%)$ & $5 / 22(23 \%)$ & $14 / 22(64 \%)$ & $1.1(0.3$ to 4.4$)$ & $0.2(0.1 \text { to } 0.7)^{*}$ & $0.2(0.1 \text { to } 0.7)^{*}$ \\
\hline
\end{tabular}

Data are presented as mean (SD), median (IQR) or $\mathrm{n}(\%)$

Between group comparisons are presented as difference in means $(95 \% \mathrm{Cl})$, differences in medians $(95 \% \mathrm{Cl})$ or odds ratios $(95 \% \mathrm{Cl})$

n/a - not available

${ }^{*}: p<0.05,{ }^{* *}: p<0.01, * * *: p<0.001$

† Daily smoker at the time of testing. 
Table 2 Static lung function and gas transfer tests compared between preterm BPD and control groups

\begin{tabular}{|c|c|c|c|c|c|c|}
\hline & $\begin{array}{l}\text { BPD } \\
(n=25)\end{array}$ & $\begin{array}{l}\text { Non BPD } \\
(n=23)\end{array}$ & $\begin{array}{l}\text { Term } \\
(n=25)\end{array}$ & BPD vs. non BPD & BPD vs.Term & Non BPD vs. Term \\
\hline $\mathrm{FEV}_{1} \%$ pred. & $88.2(15.2)$ & $102.0(14.9)$ & $109.4(11.8)$ & $-13.8(-23.5 \text { to } 4.1)^{* *}$ & $-21.2(-30.7 \text { to }-11.7)^{* * *}$ & $-7.3(-10.0$ to 2.4$)$ \\
\hline FEV $_{1}$ z-score & $-1.19(1.27)$ & $0.01(1.27)$ & $0.49(0.91)$ & $-1.20(-2.00 \text { to }-0.40)^{* *}$ & $-1.68(-2.46 \text { to }-0.89)^{* * *}$ & $-0.48(-1.27$ to 0.32$)$ \\
\hline FVC \% pred. & $101.8(15.0)$ & $110.2(13.8)$ & $115.7(9.4)$ & $-8.5(-17.5$ to 0.5$)$ & $-14.0(-22.7 \text { to }-5.2)^{* * *}$ & $-5.5(-14.4$ to 3.5$)$ \\
\hline FVC z-score & $-0.11(1.22)$ & $0.46(1.24)$ & $0.77(0.83)$ & $-0.57(-1.34$ to 0.20$)$ & $-0.88(-1.63 \text { to }-0.13)^{*}$ & $-0.31(-1.07$ to 0.46$)$ \\
\hline $\mathrm{FEV}_{1} / \mathrm{FVC}$ ratio $\%$ pred. & $75.0(9.1)$ & $80.2(9.9)$ & $81.1(7.1)$ & $-5.2(-11.3$ to 0.8$)$ & $-6.1(-12.0 \text { to }-0.2)^{*}$ & $-0.9(-6.9$ to 5.2$)$ \\
\hline $\mathrm{FEV}_{1} /$ FVC z-score & $-1.21(0.99)$ & $-0.45(1.10)$ & $-0.17(1.08)$ & $-0.76(-1.49 \text { to }-0.03)^{*}$ & $-1.05(-1.76 \text { to }-0.33)^{* *}$ & $-0.28(-1.01$ to 0.45$)$ \\
\hline $\mathrm{FEF}_{25-75} \%$ pred. & $59.0(21.5)$ & $80.7(26.0)$ & $90.8(20.3)$ & $-21.7(-37.4 \text { to }-6.1)^{* *}$ & $-31.8(-47.1 \text { to }-16.5)^{* * *}$ & $-10.1(-25.7$ to 5.6$)$ \\
\hline $\mathrm{FEF}_{25-75 \%} \mathrm{Z}$-score & $-1.55(1.34)$ & $-0.41(1.26)$ & $-0.07(0.96)$ & $-1.14(-1.97 \text { to }-0.31)^{* *}$ & $-1.48(-2.29 \text { to }-0.67)^{* * *}$ & $-0.34(-1.17$ to 0.49$)$ \\
\hline RV \% pred. & $108.6(36.7)^{a}$ & $103.5(32.1)^{b}$ & $105.6(34.2)^{c}$ & $5.1(-20.3$ to 30.6$)$ & $3.0(-21.7$ to 27.7$)$ & $-2.1(-26.8$ to 22.5$)$ \\
\hline TLC \% pred. & $104.7(15.2)^{a}$ & $105.6(10.9)^{b}$ & $110.9(12.4)^{c}$ & $-1.0(-10.5$ to 8.6$)$ & $-6.3(-15.5$ to 3.0$)$ & $-5.3(-14.6$ to 4.0$)$ \\
\hline RV/TLC ratio \% & $106.4(33.4)^{a}$ & $96.9(26.3)^{b}$ & $91.5(19.0)^{c}$ & $9.5(-10.1$ to 29.2$)$ & $15.0(-4.1$ to 34.0$)$ & $5.4(-13.6$ to 24.5$)$ \\
\hline TLco \% pred. & $87.4(16.8)^{b}$ & $90.1(12.6)$ & $104.9(11.2)$ & $-2.7(-12.4$ to 7.0$)$ & $-17.6(-27.1 \text { to }-8.1)^{* * *}$ & $-14.8(-24.3 \text { to }-5.3)^{* *}$ \\
\hline $\mathrm{K}_{\mathrm{co}} \%$ pred. & $86.5(9.7)^{d}$ & $87.1(10.9)^{c}$ & $101.5(11.3)^{b}$ & $-0.6(-8.3$ to 7.1$)$ & $-15.0(-22.6 \text { to }-7.4)^{* * *}$ & $-14.4(-22.0 \text { to }-6.8)^{* * *}$ \\
\hline Lung clearance index & $7.0(6.7$ to 7.9$)$ e & 6.1 (5.9 to 6.9$)^{a}$ & $6.6(5.9 \text { to } 7.0)^{d}$ & $0.9(0.3 \text { to } 1.2)^{* *}$ & $0.4(0.1 \text { to } 1.1)^{*}$ & $-0.5(-0.7$ to 0.3$)$ \\
\hline FeNO ppb & 19 (12 to 28$)$ & 19 (12 to 28$)$ & 27 (14 to 43 ) & $0(-6$ to 6$)$ & $-8(-15$ to 2$)$ & $-8(-16$ to 2$)$ \\
\hline
\end{tabular}

Data are presented as mean (SD) or median (IQR).

Between group comparisons made using ANOVA with Tukey-Kramer (all pairs simultaneous $95 \% \mathrm{Cl}$ ) or Kruskal-Wallis ANOVA of ranks followed by Dunn's (all pairs) test.

*: $p<0.05,{ }^{* *}$ : $p<0.01, * * *$ : $p<0.001$

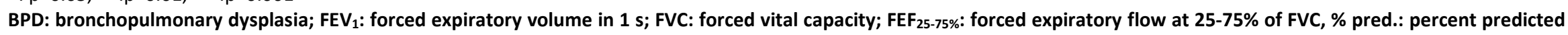
measurements; ppb: parts per billion ${ }^{a}: n=4$ missing data, ${ }^{b}: n=2$ missing data, ${ }^{c}: n=1$ missing data, ${ }^{d}: n=3$ missing data, e $: n=5$ missing data . 
Table 3 Comparison of lung function variables between small for gestational age (SGA) and appropriate for gestation age (AGA) preterm adult survivors before and after appropriate weighting for selection probabilities of BDP and non-BPD subjects.

\begin{tabular}{|c|c|c|c|c|}
\hline & SGA $(n=18)$ & AGA $(n=30)$ & SGA vs. AGA (crude) & SGA vs. AGA (weighted) \\
\hline Gestational age, wk & $30.4(2.4)$ & $27.7(2.6)$ & $2.8(1.3 \text { to } 4.3)^{* * *}$ & $2.4(1.5 \text { to } 4.1)^{* * *}$ \\
\hline FEV $_{1} \%$ pred. & $88.7(16.6)$ & $98.5(15.5)$ & $-9.8(-19.3$ to -0.2$) *$ & $-9.1(-19.1$ to 0.8$)$ \\
\hline FEV $_{1}$ z score & $-1.10(1.43)$ & $-0.32(1.31)$ & $-0.78(-1.60$ to 0.03$)$ & $-0.72(-1.58$ to 0.14$)$ \\
\hline FVC \% pred. & $101.8(15.4)$ & $108.3(14.4)$ & $-6.5(-15.3$ to 2.4$)$ & $-5.9(-15.1$ to 3.3$)$ \\
\hline FVC z score & $-0.81(1.39)$ & $0.37(1.13)$ & $-0.55(-1.29$ to 0.19$)$ & $-0.47(-1.31$ to 0.37$)$ \\
\hline FEV 1 /FVC $\%$ pred. & $75.4(8.3)$ & $78.8(10.5)$ & $-3.3(-9.2$ to 2.5$)$ & $-3.1(-9.2$ to 2.9$)$ \\
\hline FEV $_{1} /$ FVC z score & $-1.09(0.98)$ & $-0.71(1.16)$ & $-0.38(-1.04$ to 0.28$)$ & $-0.39(-1.09$ to 0.30$)$ \\
\hline FEF $25-75 \%$ pred. & $62.2(24.0)$ & $73.7(26.4)$ & $-11.5(-26.9$ to 3.8$)$ & $-10.5(-27.0$ to 6.0$)$ \\
\hline FEF $25-75$ z score & $-1.38(1.28)$ & $-0.78(1.46)$ & $-0.60(-1.44$ to 0.24$)$ & $-0.56(-1.40$ to 0.28$)$ \\
\hline RV \% pred. & $108.2(31.5)^{a}$ & $104.9(36.1)^{\mathrm{a}}$ & $3.3(-19.2$ to 25.8$)$ & $1.2(-21.4$ to 23.7$)$ \\
\hline TLC \% pred. & $103.7(13.2)^{a}$ & $106.0(13.2)^{\mathrm{a}}$ & $-2.3(-10.9$ to 6.3$)$ & $-2.5(-10.7$ to 5.7$)$ \\
\hline RV/TLC \% pred. & $108.3(32.1)^{a}$ & $98.0(28.9)^{a}$ & $10.3(-9.3$ to 29.8$)$ & $7.2(-12.6$ to 27.1$)$ \\
\hline TLco \% pred. & $87.3(12.5)^{b}$ & $89.5(16.0)$ & $-2.2(-11.4$ to 7.1$)$ & $-2.5(-10.4$ to 5.4$)$ \\
\hline Kco \% pred. & $87.3(11.6)^{a}$ & $86.6(9.6)^{b}$ & 0.7 (-5.9 to 7.3$)$ & $3.1(-4.2$ to 10.5$)$ \\
\hline lung clearance index & $6.9(6.1 \text { to } 7.0)^{c}$ & $6.6(6.1 \text { to } 7.8)^{c}$ & $0.3(-0.8$ to 0.6$)$ & Not applicable \\
\hline FeNO, ppb & $23(12 \text { to } 28)^{d}$ & 19 (12 to 28$)$ & $4(-4$ to 9$)$ & Not applicable \\
\hline
\end{tabular}

Data are presented as mean (SD) or median (IQR).

Between group comparisons made using ANOVA with Tukey-Kramer (all pairs simultaneous $95 \% \mathrm{Cl}$ )

or Kruskal-Wallis ANOVA of ranks followed by Dunn's (all pairs) test.

$*: p<0.05, * *: p<0.01, * * *: p<0.001$

SGA: small for gestational age; AGA: appropriate for gestational age; FEV 1 : forced expiratory volume in $1 \mathrm{~s}$; FVC: forced vital capacity; FEF $25-75 \%$ : forced expiratory flow at $25-75 \%$ of FVC, $\%$ pred.: percent predicted measurements. ${ }^{a} n=3$ missing data, ${ }^{b} n=2$ missing data, ${ }^{c} n=5$ missing data, ${ }^{d} n=1$ missing data. 
Table 4: Comparison of HRCT scores and radiological findings between adult preterm BPD and non-BPD survivors

\begin{tabular}{|c|c|c|c|}
\hline & $\begin{array}{l}\text { BPD } \\
(n=23)\end{array}$ & $\begin{array}{l}\text { Non BPD } \\
(n=23)\end{array}$ & Odds Ratio (95 \% Cl) \\
\hline Median score (interqartile range) & $6(4$ to 9$)$ & $2(0$ to 4$)$ & Not applicable \\
\hline Subpleural opacities & $22(96 \%)$ & $10(43 \%)$ & $28.6(3.3,250) * * *$ \\
\hline Hypoattenuation in expiration & $15(65 \%)$ & $7(30 \%)$ & $4.3(1.2,14.7) *$ \\
\hline Hypoattenuation in inspiration & $4(17 \%)$ & $0(0 \%)$ & - \\
\hline Subsegmental atelectasis & $4(17 \%)$ & $1(4 \%)$ & $4.6(0.5,45.1)$ \\
\hline Bullae & $5(22 \%)$ & $0(0 \%)$ & $-*$ \\
\hline Increased Bronchial Arterial Ratio & $1(4 \%)$ & $0(0 \%)$ & - \\
\hline Bronchiectasis & $1(4 \%)$ & $2(9 \%)$ & $0.5(0.0,5.7)$ \\
\hline Bronchial wall thickening & $1(4 \%)$ & $2(9 \%)$ & $0.5(0.0,5.7)$ \\
\hline Emphysema & $0(0 \%)$ & $1(4 \%)$ & - \\
\hline
\end{tabular}


Table 5: Exercise characteristics compared between study groups

\begin{tabular}{|c|c|c|c|c|c|c|}
\hline & $\begin{array}{l}\text { BPD } \\
(n=22)\end{array}$ & $\begin{array}{l}\text { Non BPD } \\
(n=20)\end{array}$ & $\begin{array}{l}\text { Term } \\
(n=24)\end{array}$ & BPD vs. Non BPD & BPD vs. Term & Non BPD vs. Term \\
\hline Peak $\mathrm{VO}_{2}, \mathrm{~L} / \mathrm{min}$ & $2.33(0.56)$ & $2.57(0.81)$ & $3.40(1.03)$ & $-0.24(-0.85$ to 0.38$)$ & $-1.07(-1.66$ to -0.48$) * * *$ & $-0.83(-1.44$ to -0.22$) * *$ \\
\hline Peak $\mathrm{VO}_{2}, \mathrm{~L} / \mathrm{min} \%$ predicted & $81.2(17.8)$ & $87.7(17.5)$ & $118.3(22.4)$ & $-6.5(-21.0$ to 8.0$)$ & $-37.1(-50.9$ to -23.3$) * * *$ & $-30.6(-44.8$ to -16.5$) * * *$ \\
\hline Peak $\mathrm{VO}_{2}, \mathrm{ml} / \mathrm{kg} / \mathrm{min}$ & $35.6(7.5)$ & $39.3(8.8)$ & $45.2(11.3)$ & $-3.7(-10.7$ to 3.3$)$ & $-9.6(-16.3$ to -3.0$) * *$ & $-6.0(-12.8$ to 0.9$) *$ \\
\hline Peak $\mathrm{VO}_{2}, \mathrm{ml} / \mathrm{kg} / \mathrm{min} \%$ predicted & $81.6(14.3)$ & $92.0(17.3)$ & $107.9(22.8)$ & $-10.5(-24.3$ to 3.39$)$ & $-26.4(-39.6$ to -13.2$) * * *$ & $-15.9(-28.5 \text { to }-2.4)^{*}$ \\
\hline \multicolumn{7}{|l|}{ Cardiovascular responses } \\
\hline AT as $\%$ peak $\mathrm{VO}_{2}$ & $50.5(12.8)$ & $47.6(8.1)$ & $63.3(13.9)$ & $2.9(-6.0$ to 11.8$)$ & $-12.8(-21.3$ to -4.2$) * *$ & $-15.7(-24.4$ to -6.9$) * * *$ \\
\hline Peak heart rate, bpm & $173(13)$ & $180(13)$ & $186(14)$ & $-7.3(-17.3$ to 2.7$)$ & $-12.9(-22.5$ to -3.4$) * *$ & $-5.6(-15.5$ to 4.2$)$ \\
\hline Peak heart rate, $\%$ predicted & $88.2(7.0)$ & $92.8(7.2)$ & $96.6(7.8)$ & $-4.6(-10.0$ to 0.9$)$ & $-8.4(-13.7$ to -3.2$) * * *$ & $-3.9(-9.2$ to 1.5$)$ \\
\hline \multicolumn{7}{|c|}{ Ventilatory and gas exchange responses } \\
\hline VE max, L/min & $78.3(22.7)$ & $85.1(25.7)$ & $109.5(36.2)$ & $-6.8(-28.4$ to 14.8$)$ & $-31.2(-51.8$ to -10.6$) * *$ & $-24.4(-45.5$ to -3.2$) *$ \\
\hline VE max, \% predicted & $64.0(20.5)$ & $54.6(6.9)$ & $62.9(14.6)$ & $9.4(-1.9$ to 20.7$)$ & $1.1(-9.7$ to 11.9$)$ & $-8.3(-19.4-$ to 2.7$)$ \\
\hline Vt, L & $1.75(0.45)$ & $2.27(0.77)$ & $2.75(0.67)$ & $-0.51(-0.99$ to -0.04$) *$ & $-1.00(-1.45$ to -0.55$) * * *$ & $-0.49(-0.95$ to -0.02$) *$ \\
\hline Vt, \% predicted & $84.6(23.9)$ & $88.9(19.3)$ & $96.2(14.9)$ & $-4.3(-18.8$ to 10.3$)$ & $-11.6(-25.5$ to 2.31$)$ & $-7.3(-21.6$ to 6.9$)$ \\
\hline Ventilatory reserve $\%$ & $36.3(20.4)$ & $45.4(6.9)$ & $37.1(14.6)$ & $-9.1(-20.4$ to 2.2$)$ & $-0.8(-11.5$ to 10.0$)$ & $8.3(-2.7$ to 19.4$)$ \\
\hline Peak respiratory rate & $38.6(9.1)$ & $35.3(6.3)$ & $36.0(7.2)$ & $3.2(-2.4$ to 8.9$)$ & $2.6(-2.8$ to 8.0$)$ & $-0.7(-6.2$ to 4.9$)$ \\
\hline Respiratory exchange ratio & $1.04(0.07)$ & $1.09(0.09)$ & $1.09(0.08)$ & $-0.05(-0.11$ to 0.01$)$ & $-0.06(-0.11$ to 0.00$)$ & $-0.01(-0.07$ to 0.05$)$ \\
\hline VE/VO ${ }_{2} @ A T$ & $23.9(2.0)$ & $22.8(2.4)$ & $22.2(1.7)$ & $1.1(-0.4$ to 2.6$)$ & $1.7(0.2$ to 3.2$) *$ & $0.6(-0.9$ to 2.1$)$ \\
\hline VE/VCO $2 @ A T$ & $28.1(1.9)$ & $27.0(2.9)$ & $25.9(2.3)$ & $1.1(-0.6$ to 2.9$)$ & $2.2(0.5$ to 3.9$) * *$ & $1.1(-0.6$ to 2.8$)$ \\
\hline $\mathrm{SpO}_{2}$ at peak & 96 (95 to 98 ) & 96 (95 to 97 ) & 97 (96 to 98$)$ & $0(-1$ to 1$))$ & $-1(-2$ to 0$)$ & $-1(-2$ to 0$) *$ \\
\hline Modified Borg score (0-10) & $8(7$ to 10$)$ & $9(8$ to 10$)$ & $8(8$ to 9$)$ & $-1(-1$ to 1$)$ & $0(-1$ to 1$)$ & 1 (0 to 1$)$ \\
\hline
\end{tabular}

Data are presented as mean (SD) or median (IQR).

Between group comparisons made using ANOVA with Tukey-Kramer (all pairs simultaneous $95 \% \mathrm{Cl}$ ) or Kruskal-Wallis ANOVA of ranks followed by Dunn's (all pairs) test. ${ }^{*}: p<0.05,{ }^{* *}: p<0.01, * * *: p<0.001$.

$\mathrm{FEV}_{1}$ : forced expiratory volume in $1 \mathrm{~s}, \mathrm{~L} / \mathrm{min}$ : litres per minute, $\mathrm{Vt} \mathrm{L}$ : tidal volume litres, Peak $\mathrm{VO}_{2}$ : oxygen uptake at peak exercise, AT: anaerobic threshold, VE/VO 2 @ AT:

Ventilatory equivalent for oxygen, VE/ $\mathrm{VCO}_{2} @ \mathrm{AT}$ : Ventilatory equivalent for carbon dioxide. 
Figures

Figure 1 
$\mathrm{FEV}_{1} \%$ predicted

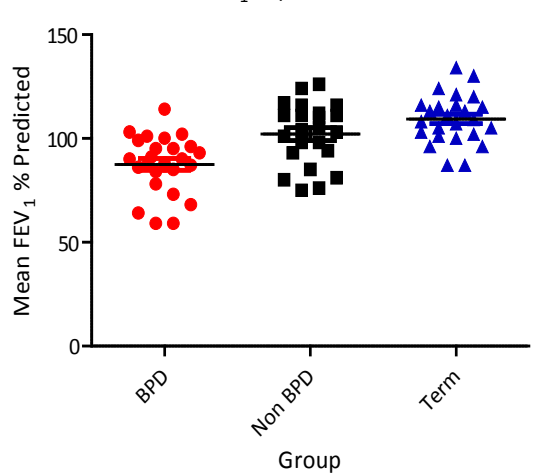

$\mathrm{FEF}_{25-75} \%$ predicted

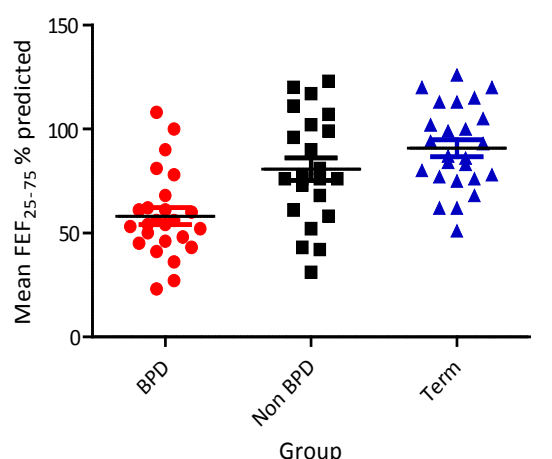

$\mathrm{FEV}_{1} / \mathrm{FVC}$ ratio

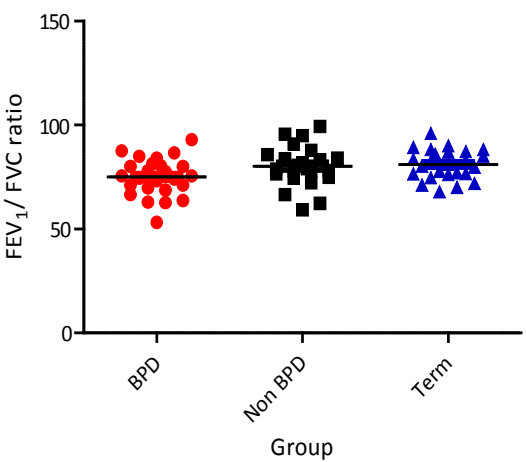

$\mathrm{K}_{\mathrm{CO}} \%$ predicted

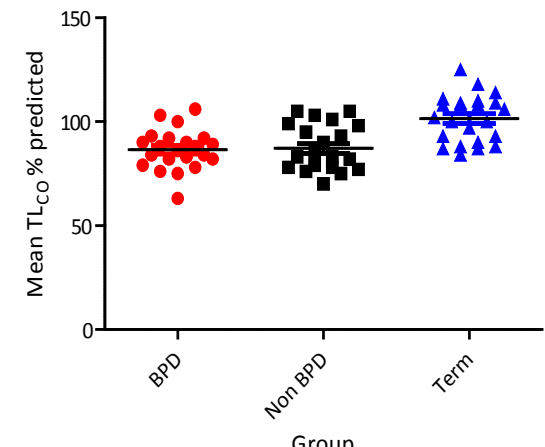

